\title{
26 \\ Digital Storytelling and \\ Diasporic Identities in Higher Education
}

\author{
Gail Benick \\ Sheridan College Institute of Technology and Advanced Learning
}

The increase in global migration to Canada has changed the demographic profile of students in Canadian higher education. Colleges and universities are becoming increasingly diverse by race, ethnicity, and culture. At the same time, the process of teaching and learning is on the cusp of transformation with technology providing the tools to alter the way post-secondary educators teach and how students learn. What pedagogical approaches have emerged to maximize educational benefit from these twin forces of migration and technology? This paper explores the use of one method that has attracted global interest: digital storytelling. Specifically, the article considers studentgenerated digital stories as a means to authenticate the multiple perspectives of learners and create space for their diverse voices in post-secondary education.

\section{Introduction}

T The increase in global migration has radically altered the demographics of Canada (Boyd $\&$ Vickers, 2000). According to the 2006 census, foreign-born people in Canada accounted for close to $20 \%$ percent (more than six million) of the total population, the highest proportion in 75 years. Between 2001 and 2006, Canada's foreign-born population increased by $13.6 \%$ - four times higher than the growth rate of $3.3 \%$ for the Canadian-born population during that same period. Approximately $60 \%$ of newcomers were from Asia, compared to $12 \%$ in $1971 ; 16 \%$ were from Europe, compared to $62 \%$ in $1971 ; 11 \%$ were from Central and South America; and 11\% were from Africa (Statistics Canada, 2007). In the past, newcomers from each of these source regions (Central and South America, as well as from Africa) accounted for less than 10\% of recent immigrants to Canada (Murdie, 2008).

The dramatic shift in immigrant origins beginning in the 1970s has contributed to the racial, ethnic, and cultural diversity of learners participating in Canadian post-secondary education today. Many immigrants who came to Canada over the last four decades now have Canadian-born children entering various stages of adulthood. Among people age 15 years and older in 2001 , nearly $17 \%$ were the children of one or more foreign-born parents (Boyd, 2008). 
These second generation Canadians are participating in post-secondary education in growing numbers. In fact, second generation Chinese and South Asian young adults are more likely than non-visible minority youth to attain university degrees (Statistics Canada, 2007). The 2001 Census data show that $40 \%$ of second generation Chinese young adults, age 20-29, living in large Census Metropolitan Areas, have bachelor's degrees or higher, and 32\% of South Asians in that cohort have achieved those academic credentials compared to $24 \%$ of nonvisible minority, third generation young adults (Boyd, 2008; Corak, 2008).

Research suggests that the trend toward increasing participation rates of second generation Canadians in higher education will continue, particularly given that the proportion of immigrants entering Canada with a university degree is on the rise. This proportion reached an historic high of 42\% among those arriving between 1995 and 2000 (Corak, 2008). As Corak (2008) states, "second generation Canadians are more educated than those whose parents were born in Canada. They have made these gains not just because their immigrant parents are more highly educated and are able to pass on this advantage... but also because, even when their parents are less educated, they are more likely to move up the schooling ladder" (p. 16). The need to embrace the diversity of students - their unique approaches to learning, their racial, ethnic and cultural backgrounds, and their multiple intelligences - has never been greater.

\section{Digital Storytelling in Higher Education}

In the last decade, digital storytelling has emerged as a practice applicable to the needs of diverse learners. Broadly defined, digital stories are personal narratives told by combining text, images, audio, and video to make short films (Coventry, 2008a). In the classic model of digital storytelling, pioneered by the Center for Digital Storytelling in Berkeley, California, digital stories are narrated in the storyteller's own voice. They are produced by using inexpensive, readily available software with a focus on compressing the elements of the film into a short piece only a few minutes long (Lambert, 2002). In contrast to commercial and professional mass media production of the industrial information age, the Center's method of computerbased storytelling favours small scale, bottom-up production employing user generated content. The latter is more characteristic of the participatory, grassroots culture created by the surge in social media (Jenkins, 2006) and reflects the tremendous leap in expressive capacity facilitated by digital technologies (Shirky, 2008).

Interest in digital storytelling has grown exponentially since the Center for Digital Storytelling initially developed their approach in the early 1990s. A robust literature now exists documenting the global popularity of digital storytelling with strongholds in North America, Great Britain, Australia, and Scandinavia (Hartley \& McWilliam, 2009; Lundby, 2008; Meadows, 2003; Ohler, 2008). The Center alone has helped to produced 12,000 digital stories. Hundreds have been displayed on the British Broadcasting Corporation's Wales website (Lundby, 2008).

The diffusion of digital storytelling in higher education has been no less remarkable. A special issue of Arts and Humanities in Higher Education highlighted the implementation of digital storytelling in universities (Coventry, 2008b) where this emergent pedagogy is utilized in a variety of fields, including literary studies, creative writing, American studies, social and cultural history, teacher training, English as a Second Language ESL, and gender studies. To date, the research supports a generally favourable view of digital storytelling as a powerful teaching and learning tool with three main benefits: increased learner engagement through valuing and validating the life experiences of students; expanded opportunities for skill building with an emphasis on the $21^{\text {st }}$ century requirement of digital, media, visual, and informational literacies; and the addition of new channels for the development of voice through multimedia authoring, an option lacking in standard essay assignments (Benick, 2011; Clarke \& Adam, 2011; Oppermann, 2008). Digital storytelling is considered particularly advantageous in classrooms 
comprised of learners from diverse racial and ethnic backgrounds because, as Benmayor (2008) notes, it's a "social pedagogy which constructs a safe and empowering space for cross-cultural collaboration and learning" (p.188).

\section{Digital Stories and Diasporic Identities}

My experience integrating digital storytelling into the course, Intercultural Communication, jointly administered by Sheridan College Institute of Technology and Advanced Learning and University of Toronto at Mississauga in the Greater Toronto Area, confirms the value of this pedagogical tool in diverse learning environments, particularly as a means of increasing awareness of cultural identity among new and second generation Canadians. Recent research on the psychosocial integration of racialized youth in Canada suggests that "multicultural settings provide opportunities for becoming aware of one's cultural identity, not only in contrast to a dominant majority, but through contact with other cultures" (Khanlou, 2008, p.55). My intercultural communication course, offered one semester annually, proved to be a case in point. In 2005, for example, the results of a course survey showed 30 different languages were represented among the 127 respondents, including Urdu, Polish, Korean, Arabic, Italian, Serbian, Swahili, Tamil, and French. The digital storytelling assignment required students to narrate an aspect of their personal or family experience pertaining to immigration, settlement, or adjustment in Canada. Equally as important, students were encouraged to show their multimedia productions in class. By investigating how their cultural identities were shaped and screening the films in a public venue, the students' stories became part of the course learning materials. After the digital stories were screened, students in the audience were required to provide written feedback assessing the impact of the movies on their understanding of immigration and settlement. Specifically, students were asked what insights regarding immigration they gained from viewing the films and in what ways their attitudes toward immigrants may have changed as a result of the screening. In this way, the diversity of the immigrant experience reflected in the movies became the thematic thread weaving the peer-to-peer learning together.

The content of the student films explored an array of experiences typically associated with the migration process - harrowing journeys to Canada, lonely first days at school, acute feelings of social difference, and ambivalent return trips to the place once called home. A Chinese student described the first leg of his family's voyage from Viet Nam to Canada, recounting how his father protected his young Vietnamese bride, the student's mother, from nightly rapes occurring on the fishing boat transporting them to a refugee camp. An Eastern European student documented his family's clandestine escape from Communist Rumania, ominously titling the film, "Don't Look Back." A Sri Lankan noted that she was embarrassed by her non-western name in kindergarten, while an Italian reported that she was humiliated by her nonna's homemade pasta in her lunchbox. An Indian student described how he felt ostracized from the boys in his neighbourhood because he lacked hockey equipment and a pair of skates. A Malaysian student lamented his boredom when he returned to his homeland for a summer vacation. In short, the students' digital stories depicted the varied and often difficult pathways from the dream of migration to settlement in Canada, suggesting a bumpy, uncertain road rather than a predictable straight line to adjustment and social inclusion (Jedwab, 2008; Kobayashi, 2008).

Although all of the films dealt with concrete places and events, the meaning of these stories, considered holistically, transcended the specific narratives described in the students' multimedia productions. Indeed, it may be more enlightening to view these digital stories as "schematic narrative templates" (Erstad \& Wertsch, 2008, p. 30) in which similar stories with different characters are told over and over, making them the basis for our collective memory and national narratives. Erstad and Wertsch (2008) call such stories cultural tools. The plots are neither new nor original. Narrative accessibility and affective impact are prioritized over formal experimentation or aesthetic innovation, enabling 
these stock tropes to become deeply embedded in our socio-cultural environment and fixed in our emotions.

While it may be too early to predict the endpoint for the first and second generation Canadians featured in these tales, the student narratives do capture turning points in the construction of their cultural and personal identities (Hull \& Katz, 2006). A prime example derives from the digital story of a Korean student who came to Canada as a 13 year old. She described the distressing conflict she faced between her fun-loving Korean self and her shy Canadian self. Imagining herself divided into two competing selves, she spoke alternatively in Korean and English throughout the film. Her moment of awakening came when she suddenly realized that she could claim both identities. In the final sequence of the film, the student, holding a Koran flag in one hand and a Canadian flag in the other, triumphantly lifted both to the sky. In another digital story, an international student described coming to the University of Toronto at Mississauga from China. Deficient in cooking skills and alone in Canada, she ate six dozen boiled eggs in her first two weeks here. On the way home from class one day, she stopped at the Chinese market and bought a package of pork chops to fry for dinner. Her efforts, however, appeared thwarted when sizzling hot oil seared the meat and burned her arm. Yet, in her assuring voiceover, the student pinpointed this potentially harmful experience as a turning point. With more practice, she said, her cooking improved, and in time, she learned to fit into her new environment as well. In these films and many others which focused on navigating the challenges of migration, students came to understand the complex world they live in and their agency in creating a place for themselves in it. Given the increasing inflows of international students (Statistics Canada, 2011) who maintain ties with family and social networks beyond the borders of Canada and the mounting number of transnational migrants who function in two social fields, the opportunity to explore cultural bifocality (Vertovec, 1999) through digital storytelling can not only be timely, but also valuable for students facing a range of barriers.
In my Intercultural Communication course, the benefits for students participating in the digital story project were two-fold. As generators of digital stories, students became more firmly anchored in their kinship networks and communities of belonging. They researched the immigration and settlement experiences of their parents and grandparents, sometimes uncovering family photo albums tucked away in basements or attics (Benick, 2011). An increased understanding of parental sacrifices emerged from this assignment, as well as an eagerness to share the digital stories with those relatives remaining in the family's country of origin. As an audience, students appreciated the opportunity to view the personal side of immigration rather than the official and statistical picture typically provided in lectures and textbooks. Alternate versions of immigration began to emerge during the in-class screening process as student started to question their assumptions about immigrants presented in the media.

\section{Conclusion}

Jean Burgess (2006) called digital storytelling an act of "vernacular creativity" based on everyday language and the informal communicative practice of telling personal stories. As a movement, Burgess noted, digital storytelling is "explicitly designed to amplify the ordinary voice" (p. 205-206) and to legitimate it as a worthy contribution to public culture.

In higher education, digital storytelling has emerged as an alternative medium of knowledge production recognizing diverse voices and mother tongues previously undervalued in the academy. At the same time, digital storytelling authenticates ways of knowing that fall outside of the expert paradigm. From a teaching and learning perspective, the practice of digital storytelling privileges intuitive and local knowledge drawn from non-academic sources, most often lived experience and memory. This openness to different forms of knowledge building and the recognition of a multiplicity of voices in the classroom may well be digital storytelling's most enduring legacy to post-secondary education. 
Digital storytelling is one pedagogical tool that can be used to increase inclusivity in postsecondary classrooms. Other inclusive pedagogies range from the incorporation of collaborative problem solving to alternative assessment techniques. As the demographic profile of students in higher education continues to change, new spaces must be provided for learners to gain knowledge in diverse ways, to imagine and create.

\section{Resources}

Benick, G. (2011). Digital storytelling and the pedagogy of human rights. Journal of Cultural Research in Art Education, 29, 37-46.

Benmayor, R. (2008). Digital storytelling as a signature pedagogy for the new humanities. Arts and Humanities in Higher Education, 7(2), 188-204.

Boyd, M. (2008).Variations in socioeconomic outcomes of second generation young adults. Canadian Diversity, 6(2), 20-24.

Boyd, M. \& Vickers, M. (2000). 100 years of immigration. Canadian Social Trends, 2-12.

Burgess, J. (2006). Hearing ordinary voices: Cultural studies, vernacular creativity and digital storytelling. Continuum: Journal of Media \& Cultural Studies, 20(2), 201-214.

Clarke, R. \& Adam, A. (2011). Digital storytelling in Australia: Academic perspectives and reflections. Arts and Humanities in Higher Education 2 10(3), 1-20.

Corak, M. (2008). Immigration in the long run: The education and earnings mobility of secondgeneration Canadians. Choices, 14(13), 4-28.

Coventry, M. (2008a). Cross-currents of pedagogy and technology: A forum on digital storytelling and cultural critique: Introduction. Arts and
Humanities in Higher Education, 7(2), 165170.

Coventry, M. (Ed.). (2008b). Cross-currents of pedagogy and technology: A forum on digital storytelling and cultural critique. Arts and Humanities in Higher Education, 7(2).

Erstad, O. \& Wertsch, V. (2008). Tales of mediation: Narrative and digital media as cultural tools. In K. Lundby (Ed.), Digital storytelling, mediatized stories: Self representation in new media (pp. 21-41). New York: Peter Lang.

Hartley, J. \& McWilliam, K. (Eds.). (2009). Story circle: Digital storytelling around the world. Malden, MA: Wiley-Blackwell.

Hull, G. \& Katz, M-L. (2006). Crafting an agentive self: Case studies on digital storytelling. Research in the Teaching of English, 41(1), 4381.

Jedwab, J. (2008). The rise of the unmeltable Canadians? Ethnic and national belonging in Canada's second generation, Canadian Diversity, 6(2), 25-34.

Jenkins, H. (2006). Confronting the challenges of participatory culture: Media education in the $21^{\text {st }}$ century. Retrieved from http:// newmedialiteracies.org/files/working/ NMLWhitePaper.pdf

Khanlou, N. (2008). Psychosocial integration of second and third generation racialized youth in Canada. Canadian Diversity, 6(2), 54-57.

Kobayashi, A. (2008). A research and policy agenda for second generation Canadians: Introduction. Canadian Diversity, 6(2), 3-6.

Lambert, J. (2002). Digital storytelling. Berkeley, CA: Digital Diner Press.

Lundby, K. (Ed.). (2008). Digital storytelling, 
mediatized stories: Self representation in new media. New York: Peter Lang.

Meadows, D. (2003). Digital storytelling: researchbased practice in new media. Visual Communication, 2(2), 189-193.

Murdie, R. (2008). Diversity and concentration in Canadian immigration (Research Bulletin No. 42). Toronto, ON: Centre for Urban \& Community Studies, University of Toronto.

Ohler, J.B. (2008). Digital storytelling in the classroom: New media pathways to literacy, learning and creativity. Thousand Oaks CA: Corwin Press.

Oppermann, M. (2008). Digital storytelling and American studies. Critical trajectories from the emotional to the epistemological. Arts and Humanities in Higher Education, 7(2), 171-187.

Shirky, C. (2008). Here comes everybody. New York: Penguin.

Statistics Canada. (2007). Retrieved from http:// www.statcan.gc.ca/dailyquotidien/071204/ dq071204a-eng.htm

Statistics Canada. (2011). Retrieved from http:// www.statcan.gc.ca/pub/81-004-x/2010006/ article/11405-eng.htm

Vertovec, S. (1999). Conceiving and researching transnationalism. Ethnic and Racial Studies, 22(2), 1-14.

\section{Biography}

Gail Benick is a Professor at Sheridan College Institute of Technology and Advanced Learning in the Faculty of Humanities and Social Sciences. Her teaching and research focus on Canadian immigration, diversity, and human rights. 